\title{
Ion Mobility Spectrometry-Mass Spectrometry Performance Using Electrodynamic Ion Funnels and Elevated Drift Gas Pressures
}

\author{
Erin Shammel Baker, Brian H. Clowers, Fumin Li, Keqi Tang, \\ Aleksey V. Tolmachev, David C. Prior, Mikhail E. Belov, \\ and Richard D. Smith \\ Biological Sciences Division and Environmental Molecular Sciences Laboratory, Pacific Northwest National \\ Laboratory, Richland, Washington, USA
}

The ability of ion mobility spectrometry coupled with mass spectrometry (IMS-MS) to characterize biological mixtures has been illustrated over the past eight years. However, the challenges posed by the extreme complexity of many biological samples have demonstrated the need for higher resolution IMS-MS measurements. We have developed a higher resolution ESI-IMS-TOF MS by utilizing high-pressure electrodynamic ion funnels at both ends of the IMS drift cell and operating the drift cell at an elevated pressure compared with that conventionally used. The ESI-IMS-TOF MS instrument consists of an ESI source, an hourglass ion funnel used for ion accumulation/injection into an $88 \mathrm{~cm}$ drift cell, followed by a $10 \mathrm{~cm}$ ion funnel and a commercial orthogonal time-of-flight mass spectrometer providing high mass measurement accuracy. It was found that the rear ion funnel could be effectively operated as an extension of the drift cell when the DC fields were matched, providing an effective drift region of $98 \mathrm{~cm}$. The resolution of the instrument was evaluated at pressures ranging from 4 to 12 torr and ion mobility drift voltages of $16 \mathrm{~V} / \mathrm{cm}$ (4 torr) to $43 \mathrm{~V} / \mathrm{cm}$ (12 torr). An increase in resolution from 55 to 80 was observed from 4 to 12 torr nitrogen drift gas with no significant loss in sensitivity. The choice of drift gas was also shown to influence the degree of ion heating and relative trapping efficiency within the ion funnel. (J Am Soc Mass Spectrom 2007, 18, 1176-1187) (c) 2007 American Society for Mass Spectrometry

$\mathrm{D}$ eveloping an effective analytical method to characterize extremely complex biological systems is one of the most difficult challenges in analytical chemistry. While many methods have been explored for this purpose, the high throughput capabilities of mass spectrometry (MS) and its ability to directly sample biomolecules out of solution using electrospray ionization (ESI) [1] are particularly suited to this task. Despite advances in this field, due to the broad range of analytes and their varying signal intensities within a complex sample, the ability to comprehensively detect a wide dynamic range of analytes in a single analysis remains limited. To address this problem, various separation methods capable of fractionation before MS analysis have been employed [2, 3], specifically liquid chromatography (LC) [4] and ion mobility spectrometry (IMS) [5-7]. Thus, the methods of LC-MS [4], IMS-MS [8, 9], and even LC-IMS-MS [10, 11] have all been utilized in analyzing biological samples.

Address reprint requests to Dr. R. D. Smith, Biological Sciences Division and Environmental Molecular Sciences Laboratory, Pacific Northwest National Laboratory, 3335 Q Ave. (K8-98), P.O. Box 999, Richland, WA 99352, USA. E-mail: rds@pnl.gov
While LC-MS allows analysis of the retention time and $\mathrm{m} / \mathrm{z}$ for each biomolecule in a sample [12, 13], a significant limitation to this technique is its speed since separations may take from minutes to several hours. On the other hand, IMS offers the basis for much faster separations when coupled with MS [8,9]. IMS is based on the fact that species with different collision cross sections travel with different velocities (i.e., ion mobilities) when they are pulled by a weak electric field through a drift cell filled with a buffer gas [14]. By coupling IMS to TOF MS, samples can be separated based on size and $\mathrm{m} / \mathrm{z}$ very quickly due to the high speed of IMS separations ( $\sim 10$ to $100 \mathrm{~ms})$ and TOF MS detection $(\sim 100 \mu \mathrm{s})[8,9]$.

For the analysis of complex mixtures with IMS-MS, one desires the highest IMS resolution possible. Since the diffusion-limited maximum resolving power of IMS is given by [15]

$$
\frac{t_{D}}{t_{1 / 2}}=\frac{1}{4}\left(\frac{q}{k_{b} \ln 2}\right)^{1 / 2}\left(\frac{V}{T}\right)^{1 / 2}
$$

where $t_{D}$ is the drift time, $t_{1 / 2}$ is the width of the peak at half-height, $q$ is the charge of the ion, $V$ is the voltage 


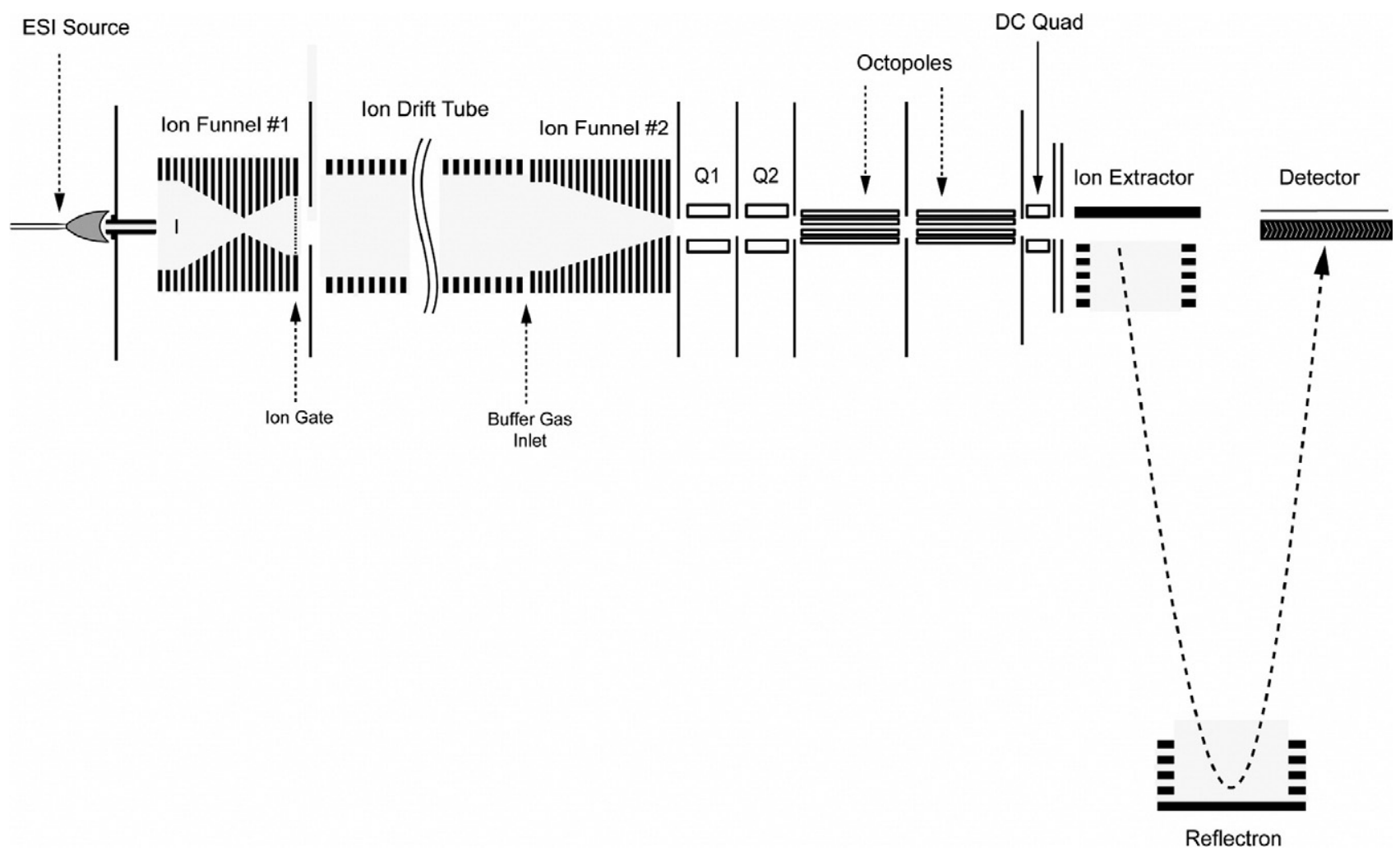

Figure 1. A schematic diagram of the newly designed ESI-IMS-TOF MS.

drop across the drift cell, $k_{b}$ is Boltzmann's constant and $T$ is temperature; clearly to increase the resolving power it is necessary to increase the voltage across the drift cell or decrease the temperature. However, the temperature used for this study was limited to ambient conditions, thus increasing the voltage was the most direct means to influence resolution.

For precise IMS measurements it is essential to keep the ions in the low field limit, which is defined by the maximum $E / N$ ( $E$ is the drift field and $N$ is the number density of the buffer gas) where the mobility of an ion is still independent of the drift field [14]. Thus, to increase the voltage across the drift cell, it is necessary to increase the pressure in the drift cell. In this paper, we report on the design and data from a new ESI-IMSTOF MS instrument that incorporates electrodynamic ion funnels before and after the drift cell allowing the drift cell pressure to be increased from 4 to 12 torr, providing increased IMS resolution.

\section{Experimental}

\section{Materials}

Samples used to evaluate the performance of the ESIIMS-TOF MS included leucine enkephalin, reserpine, bradykinin, bovine ubiquitin, bovine cytochrome $c$, bovine serum albumin, and equine skeletal muscle myoglobin, which were purchased from Sigma Chemical Company (St. Louis, MO) and used without further purification. Solutions were diluted to desired concentrations (usually between 1 to $5 \mu \mathrm{M}$ ) using solvents of water:methanol:acetic acid, 49.5:49.5:1 (vol/vol/vol) or $25 \mathrm{mM}$ ammonium bicarbonate:acetic acid, 99.5:0.5 (vol/vol). All samples were ionized in positive ESI mode and directly infused at a flow rate of $0.3 \mu \mathrm{L} / \mathrm{min}$. The tryptic digestion of $0.1 \mathrm{mg} / \mathrm{mL}$ of BSA was performed following the procedures outlined in reference [16]. Ultra-pure nitrogen and helium gases (>99.9999\%) were utilized for all experiments presented.

\section{Instrumentation}

A schematic of the ESI-IMS-TOF MS equipped with two electrodynamic ion funnels to maximize ion transmission is shown in Figure 1. This instrument is comprised of six primary components: (1) an ESI source; (2) a high-pressure hourglass ion funnel to focus ions before ion injection; (3) an ion gate; 4) an ion mobility drift cell; (5) a secondary high-pressure ion funnel to focus the diffused ion beam post-IMS separation; and (6) an orthogonal TOF MS to measure mass to charge ratios $(\mathrm{m} / \mathrm{z})$ of the ions after IMS separation. The drift cell used the same modular design concept with each modular unit floated at different voltage as previously reported [17]. Compared with its predecessor, the current platform features two primary modifications. The first was replacing the standard ion funnels operating at low pressures ( $\leq 4.0$ torr) with ion funnels capable of oper- 
ating at higher pressures while maintaining comparable ion transmission [18]. This modification was very important since increasing pressure allows higher electric fields to be attained and consequently higher IMS resolving power. The second alteration was coupling an orthogonal TOF MS (Agilent Technologies, Santa Clara, CA) by adding two differentially pumped short quadrupole chambers at the IMS and TOF MS interface (Q1 and Q2 in Figure 1) to facilitate the high-pressure IMS operation.

\section{ESI Source and Electrodynamic Hourglass Ion Funnel}

The ESI source and interface consist of an ESI emitter, capillary inlet, and an hourglass-shaped ion funnel. The source was electrically floated above the IMS voltage using adjustable RF and DC power supplies, and all voltages mentioned in this section were referenced to the IMS drift voltage. Sample solutions were ionized using a chemically etched fused-silica emitter $(20 \mu \mathrm{m}$ i.d. $/ 150 \mu \mathrm{m}$ o.d., at a potential of $2.6 \mathrm{kV})[19]^{\circ}$ and transported through a heated capillary inlet $(0.43 \mathrm{~mm}$ i.d. ${ }^{\circ} \times^{\circ} 64^{\circ} \mathrm{mm}^{\circ}$ at $\left.^{\circ} 120^{\circ} \mathrm{C}^{\circ}[20]\right) .{ }^{\circ}$ Once ${ }^{\circ}$ through ${ }^{\circ}$ the $e^{\circ}$ heated capillary, the ions were transmitted into a high-pressure hourglass ion funnel with effective operating pressure up to 30 torr. This hourglass ion funnel, similar to the previous $^{\circ} \operatorname{design}^{\circ}[17],{ }^{\circ} \operatorname{consists}^{\circ}$ of $^{\circ} 100^{\circ}$ brass $^{\circ}$ ring $^{\circ}$ elec- $^{-}$ trodes $(0.5 \mathrm{~mm}$ thick electrodes insulated by $0.5 \mathrm{~mm}$ Teflon spacers). The excess material from each electrode was removed to reduce the total funnel capacitance from $\sim 6.0$ to $1.6 \mathrm{nF}$ and increase the funnel RF operating frequency and amplitude for effective ion transmission at ${ }^{\circ}$ high-pressure $[18]$. There $^{\circ}$ were ${ }^{\circ}{ }^{\circ}$ so $^{\circ}$ four ${ }^{\circ}$ distinct sections instead of the three in the previous design to optimize the ion capacity. The first section contained 24 electrodes, with i.d. $=25.4 \mathrm{~mm}$; the second section contained 42 electrodes with i.d. linearly decreasing from 25.4 to $2.0 \mathrm{~mm}$; the third section housed 24 electrodes with i.d. increasing linearly from 2.1 to $20.0 \mathrm{~mm}$; and the final section was comprised of 10 electrodes with $20 \mathrm{~mm}$ i.d. that extend to the funnel exit. As with a traditional ion funnel, both RF and DC voltages were applied simultaneously to each electrode. For the experiments reported in this manuscript, the RF frequency and amplitude were $865 \mathrm{kHz}$ and $100 \mathrm{~V}_{p-p}$ (peak-to-peak). A DC bias of $225 \mathrm{~V}$ was applied on the first funnel electrode and $65 \mathrm{~V}$ on the last to produce an axial DC field of $16 \mathrm{~V} / \mathrm{cm}$ in the funnel. In addition to the four sections described above, a singular brass disk, or $^{\circ}$ jet-disruptor ${ }^{\circ}\left[21,{ }^{\circ} 22\right]^{\circ}$ with $^{\circ}$ an $^{\circ}$ o.d..$^{\circ}$ of $^{\circ} 6.5^{\circ} \mathrm{mm}^{\circ}$ and voltage of $200 \mathrm{~V}$, was positioned on a concentric axis 20 $\mathrm{mm}$ from the entrance of the ion funnel. The jet disruptor effectively diffused the directed gas flow from the free-jet expansion exit of the heated capillary and maintains optimum ion transmission through the ion funnel.

Similar ${ }^{\circ}$ to $^{\circ}$ the $^{\circ}$ previous $^{\circ}$ hourglass $^{\circ}$ ion $^{\circ}$ funnel $^{\circ}$ [17] a high-transmission grid (20 lines-per-in.; Buckbee-
Mears, St. Paul, MN) located $2 \mathrm{~mm}$ behind the terminal ion funnel electrode was utilized as an ion gate. The gate was pulsed by a rectangular waveform with open and closed gating voltages of 50 and $78 \mathrm{~V}$. The frequency and duration of the gating pulse was defined by the user with a typical opening time of $100 \mu$ s and frequency of $10 \mathrm{~Hz}$.

\section{Ion Mobility Drift Cell}

Modeled after the drift cell design previously reported

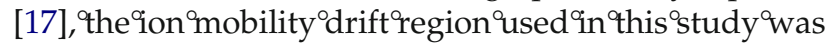
constructed using four modular ion mobility units (total $\mathrm{L}=88 \mathrm{~cm})$. Each unit consisted of 21 copper ring electrodes (i.d $=55 \mathrm{~mm}$, o.d. $=80 \mathrm{~mm}$ ) separated by 10 $\mathrm{mm}$ Teflon spacers and housed in a $20 \mathrm{~cm}$ long cylindrical chamber (i.d. $=20 \mathrm{~cm}$, nonmagnetic steel). Each drift cell unit was electrically insulated and vacuum sealed using a PEEK spacer $(233 \mathrm{~mm}$ o.d. $\times 55 \mathrm{~mm}$ i.d. $\times 1 \mathrm{~cm})$. After applying the ion mobility drift voltage using a four-channel 10-kV DC power supply (Ultravolt, Ronkonkoma, NY), the electric field gradient within the ion mobility cell was established by connecting each ring electrode in series using high precision $1 \mathrm{M} \Omega$ resistors. Filtered high purity nitrogen or helium gases were used as buffer gases for the experiments described in this paper. Two capacitance manometers (MKS, Wilmington, MA) were used to monitor the gas pressures in the IMS and hourglass ion funnel chambers. Throughout the experiments, a positive gas flow from the drift cell into source chamber, measured as a 0.06 torr difference, was maintained to minimize the entrance of neutral molecules into the drift cell. Additionally, all experiments were conducted at room temperature $\left(\sim 19.5^{\circ} \mathrm{C}\right)$.

\section{Rear High Pressure Ion Funnel}

$\mathrm{As}^{\circ}$ demonstrated $^{\circ}$ previously $^{\circ}[17],{ }^{\circ}$ an $^{\circ}$ ion $^{\circ}$ funne ${ }^{\circ}$ with wide acceptance in the IMS-MS region can refocus the diffused ion beam following IMS separation without compromising IMS resolving power. Similar to the hourglass design outlined in a previous section, this ion funnel was also modified to operate at a higher pressure by reducing the overall capacitance and it consists of 100 brass ring electrodes, each $0.5 \mathrm{~mm}$ thick and insulated by $0.5 \mathrm{~mm}$ Teflon spacers. This ion funnel has two primary regions. The first region consisted of 66 electrodes with a constant $25.4 \mathrm{~mm}$ i.d. and the second region is comprised of 44 electrodes with i.d. decreasing linearly from $25.4 \mathrm{~mm}$ to $2.0 \mathrm{~mm}$. The RF frequency and amplitude were $950 \mathrm{kHz}$ and $100 \mathrm{~V}_{p-p}$ (peak-to-peak). While the applied potential to the last IMS electrode and the first ion funnel electrode vary with IMS pressures (to maintain a constant field in the IMS and rear ion funnel regions), the last ion funnel electrode was held constant at $88 \mathrm{~V}$. 


\section{Orthogonal Acceleration TOF MS}

An orthogonal acceleration time-of-flight mass spectrometer (oTOF MS, Agilent Technologies) was used for accurate mass measurement of mobility separated ions. To accommodate high-pressure IMS operation, two differentially pumped short quadrupole ( $24 \mathrm{~mm}$ long) chambers $^{\circ}\left(\mathrm{Q} 1^{\circ} \text { and }{ }^{\circ} \mathrm{Q} 2^{\circ}{ }^{\circ}{ }^{\circ} \text { Figure }^{\circ} 1\right)^{\circ}$ were $^{\circ}$ used $^{\circ}$ after ${ }^{\circ}$ the rear ion funnel. An Edwards E2M80 was used for the Q1 chamber and the roughing pump (Edwards E2M30) for Agilent TOF MS was used for the Q2 chamber. The pressure in the Q2 chamber was maintained at 0.22 torr for all drift cell pressures ( 4 to 12 torr) in the experiment to minimize the ion transient time between IMS and TOF detector. Both quadrupoles were operated with a RF frequency and amplitude of $1.10 \mathrm{MHz}$ and $200 \mathrm{~V}_{p-p}$ (peak-to-peak). Two DC-only conductance limit electrodes ( $0.5 \mathrm{~mm}$ thick brass) with $2.5 \mathrm{~mm}$ apertures were used to separate Q1, Q2, and the first octopole of the TOF MS. The bias voltages applied to Q1, the Q1 conductance limit, Q2, and the Q2 conductance limit were set at $68,63,48$, and $43 \mathrm{~V}$, respectively.

A $10 \mathrm{GHz}$ time-to-digital converter (TDC) (Ortec 9353; Oak Ridge, TN) was used to record the ion counts from the oTOF detector for ion mobility measurements. The TOF MS pusher signal was used to synchronize the timing sequences of IMS pulsing, and the data acquisitions were controlled using a National Instruments PCI-6711 (Austin, TX). The detailed description of the instrumental control software and data acquisition scheme ${ }^{\circ}{ }^{\circ}{ }^{\circ}$ been $^{\circ}{ }^{\text {reported }}{ }^{\circ}$ previously ${ }^{\circ}[17]$.

\section{Data Analysis}

To quantitatively measure the mobility and collision cross section of a ion, the following procedure was utilized $^{\circ}[23-25]^{\circ}{ }^{\circ}$ First $^{\circ}{ }^{\circ}{ }^{\circ}$ pulse $^{\circ}$ of $^{\circ}$ ions $^{\circ}$ was $^{\circ}$ injected ${ }^{\circ}$ at low-energy into a drift cell filled with a buffer gas (helium or nitrogen), where a weak, homogeneous electric field, $E$, is applied across the cell causing the ion packet to drift towards the exit of the cell. Collisions with the buffer gas broaden the ion packet width and serve to bring a balance between the force imposed by the electric field and the frictional drag. As a consequence, the ions drift at constant velocity, $v_{d}$, proportional ${ }^{\circ}$ to ${ }^{\circ}$ the ${ }^{\circ}$ applied ${ }^{\circ}$ field $^{\circ} E$ as $^{\circ}$ shown $^{\circ}$ in $^{\circ} \mathrm{eq}^{\circ} 2^{\circ}[14]$ :

$$
v_{d}=K \cdot E
$$

where the proportionality constant, $K$ (in $\mathrm{cm}^{2} / \mathrm{V} \cdot \mathrm{s}$ ), is termed the mobility of the ions. However, since $K$ is dependent on the number density of the buffer gas, it is usually standardized (as shown in eq 3) with respect to molecular number density and the reduced mobility, $K_{o}$, is usually reported with $T$ being the drift cell temperature in Kelvin and $p$ being the buffer gas pressure in torr.

$$
K_{o}=K \cdot \frac{p}{760} \cdot \frac{273.16}{T}
$$

In the experiments detailed in this paper, reduced mobilities were determined by collecting arrival time distributions (ATDs) at five different drift voltages. The arrival time, $t_{A}$, of a particular ion is extracted from the center of the ATD peak. Since $t_{A}$ is the average amount of time it takes for an ion to travel from the source of an instrument to the detector, $t_{A}=t_{d}+t_{o}$, where $t_{d}$ is the time the ion spends in the drift cell and $t_{o}$ is the time the ion spends between the exit of the drift cell and the MS detector. From eq 2 and eq 3 and the fact that $v_{d}=1 / \mathrm{t}_{d}$ and $E=V / l$ (where $l$ is the length of the drift cell and $V$ is the voltage drop across the cell), $t_{A}$ can be written as:

$$
t_{A}=\frac{l^{2}}{K_{o}} \cdot \frac{273.16}{760 T} \cdot \frac{p}{V}+t_{o}
$$

The expression for $t_{A}$ in eq 4 has a linear dependence on $p / V$ where the slope of the line is inversely proportional to $K_{o}$ and the y-intercept is equal to $t_{o}$. To acquire $K_{o}, t_{A}$ is extracted from the center of the ATD peak and plotted against $p / V . t_{A}$ versus $p / V$ plots display a high degree of linearity with correlation values of at least 0.9999 indicating that the drift time (e.g., mobility) measurements are independent of the electric field.

The mobility of an ion is dependent on the number of collisions it encounters with the buffer gas. By measuring the mobility of an ion, information about the ion's shape and size or, in other words, collision cross section, can be determined. The relationship between the mobility of an ion and its collision cross section has been ${ }^{\circ}$ derived ${ }^{\circ}$ in $^{\circ}$ detail $^{\circ}$ using $^{\circ}$ kinetic $^{\circ}$ theory ${ }^{\circ}[14]^{\circ}$ and $^{\circ}$ is given by:

$$
K_{o}=\frac{3 q}{16 N_{o}} \cdot\left(\frac{2 \pi}{\mu k_{b} T}\right)^{1 / 2} \cdot \frac{1}{\Omega}
$$

where $q$ is the ion charge, $N_{o}$ is the buffer gas density at standard temperature and pressure (STP), $\mu$ is the reduced mass of the collision partners, $k_{b}$ is Boltzmann's constant and $\Omega$ is the momentum transfer collision integral ${ }^{\circ}$ also $^{\circ}$ termed ${ }^{\circ}$ the ${ }^{\circ}$ collision $^{\circ}$ cross $^{\circ}$ section $^{\circ}[26]^{\circ}{ }^{\circ}$ To minimize error in the experimental evaluation of $\Omega$, multiple measurements were made on each system studied. The reproducibility was determined to have less than $1 \%$ error with small variations most likely due to small pressure fluctuations during the measurement.

\section{Results and Discussion}

\section{Ion Funnel Evaluation}

To maximize ion transmission and effectively sensitivity, an increasing number of ion mobility systems are 
utilizing technology based upon the electrodynamic ion funnel $l^{\circ}\left[17,{ }^{\circ} 18,{ }^{\circ} 27-30\right] .{ }^{\circ}$ As ${ }^{\circ}$ outlined ${ }^{\circ}$ in ${ }^{\circ}$ the ${ }^{\circ}$ experimental section, an electrodynamic ion funnel commonly consists of a series of conducting electrodes that possess apertures that decrease in diameter with each successive element. The electrodes that produce the funnellike profile are connected both by a series of resistors and capacitors. The resistive series serves to establish a DC electric field, while the capacitive series permits an alternating RF potential to be applied to the system. As the instrumental principles governing ion focusing differ significantly with ion mobility spectrometry, questions regarding the impact of the ion funnel on IMS measurements must be answered. Previous efforts have illustrated the independence of ion mobility resolving power on the RF potentials applied to the rear ion funnel ${ }^{\circ}$ in $^{\circ} a^{\circ}$ system $^{\circ}$ as $^{\circ}$ outlined ${ }^{\circ}$ in $^{\circ}$ Figure $^{\circ} 1^{\circ}[17] .{ }^{\circ}$ However, the quantitative effects of the DC electric field gradient were not addressed. To further characterize the performance of electrodynamic ion funnels with IMS, ${ }^{\circ}$ Figure $2^{\circ}$ displays ${ }^{\circ}$ the ${ }^{\circ}$ results $^{\circ}$ of $^{\circ}$ an $^{\circ}$ experiment that varies the DC electric field strength of the rear ion

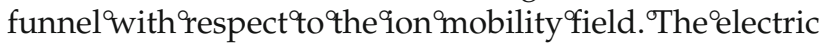
field within the ion mobility drift cell at 4 torr nitrogen ranged from $\sim 13$ to $\sim 22 \mathrm{~V} / \mathrm{cm}$ and $\sim 3$ to $\sim 22 \mathrm{~V} / \mathrm{cm}$ in the rear ion funnel. Each arrival time distribution (ATD) of (bradykinin $)^{2+}{ }^{\circ}$ shown in Figure 2 was ${ }^{\circ}$ defined by two parameters: (1) ion mobility drift cell field strength; (2) relative ion funnel field strength (referenced to the ion mobility ${ }^{\circ}$ electric $^{\circ}$ field). ${ }^{\circ}$ Figure $^{\circ} 2 \mathrm{a}^{\circ}$ displays ${ }^{\circ}$ the ${ }^{\circ} \mathrm{ATD}^{\circ}$ of bradykinin $[\mathrm{M}+2 \mathrm{H}]^{2+}$ when the field strength of the drift cell and ion funnel were equal $(0 \mathrm{~V} / \mathrm{cm}$ difference). The ${ }^{\circ}$ second ${ }^{\circ}$ plot, ${ }^{\circ}$ Figure $2 \mathrm{~b}$, ${ }^{\circ}$ shows ${ }^{\circ}{ }^{\circ}$ similar $^{\circ}$ distribution of drift times when the ion funnel electric field was held

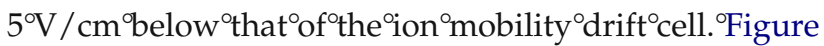
$2 \mathrm{c}^{\circ}$ follows ${ }^{\circ}$ this $^{\circ}$ same $^{\circ}$ trend $^{\circ}{ }^{\circ}$ with $^{\circ}$ the $^{\circ}$ shift $^{\circ}$ in $^{\circ}$ drift $^{\circ}$ times $^{\circ}$ for ion funnel fields $10 \mathrm{~V} / \mathrm{cm}$ below that of the drift cell.

Figure $^{\circ} 2^{\circ}$ illustrates ${ }^{\circ}$ that $^{\circ}$ the $^{\circ}$ resolving $^{\circ}$ power $^{\circ}$ of $^{\circ}$ bradykinin $[\mathrm{M}+2 \mathrm{H}]^{2+}$ was degraded when the ion funnel field was held below the drift cell field, however, the resolving power was not significantly degraded except when a drift potential of $1.4 \mathrm{kV}$ or lower was used and the IMS drift cell field was $10 \mathrm{~V} / \mathrm{cm}$ higher than the ion funnel field. To further understand the effect of unmatched fields, ion funnel electric fields held 5 and 10 $\mathrm{V} / \mathrm{cm}$ higher than the drift cell field were also evaluated (not shown). The peaks in these graphs had similar resolution and sensitivity as those of the matched field $\left(0^{\circ} \mathrm{V} / \mathrm{cm}\right)^{\circ}$ in ${ }^{\circ}$ Figure $2 \mathrm{a}$, but $^{\circ}$ analogous ${ }^{\circ}{ }^{\circ}$ Figure $2 \mathrm{~b}^{\circ}$ and ${ }^{\circ} \mathrm{C}$ there was a shift in drift times. This leads to the question of whether the ion funnel acts as an extension of the drift cell. To evaluate this issue, the experimental drift $^{\circ}$ times $^{\circ}$ of ${ }^{\circ}$ bradykinin ${ }^{\circ}\left[\mathrm{M}^{\circ}+{ }^{\circ} 2 \mathrm{H}\right]^{2+}{ }^{\circ}$ in $^{\circ}$ Figure ${ }^{\circ} 2^{\circ}$ were compared with their corresponding theoretical drift times, calculated using the field strength of the ion mobility drift cell and ion funnel and summing the times in each region together. Since minimal deviations between the theoretical and experimental drift times were observed, it can be concluded that the $10 \mathrm{~cm}$ rear ion funnel acts as an extension to the $88 \mathrm{~cm}$ drift cell, allowing a $98 \mathrm{~cm}$ drift region to exist in the ESI-IMS-TOF MS.

Because the ion funnel acts as an extension to the drift cell, matched drift cell and ion funnel fields are required for calculating an ion's cross section with the greatest accuracy. To calculate an ion's cross section with maximum accuracy, $p / V$ versus $t_{A}$ plots are acquired for at least five different $V$ s. From these plots, the time an ion spends outside of the drift cell ( $t_{o}$ from eq 4) is accurately calculated from the y-intercept. However, $V$ must be constant throughout the drift region for $p / V$ versus $t_{A}$ plots, so they cannot be used with unmatched fields and, consequently, $t_{o}$ cannot be calculated. A single $V$ calculation of cross section can be used when $l^{2} / V$ for the IMS drift cell and the ion funnel are supplied independent of each other. However, $t_{o}$ varies for each ion and must be approximated causing the calculated cross sections to not be as accurate as those obtained from the $p / V$ versus $t_{A}$ plots. Thus, since no resolution or sensitivity gain was observed when the drift cell and ion funnel fields were not held at the same field, matched fields should be utilized to allow the most accurate evaluation of cross section.

\section{Resolving Power}

Ion mobility resolving power $\left(\mathrm{R}_{\mathrm{p}}\right)$ has been traditionally defined as the drift time of an ion divided by the ion packet width measured at half-height of the signal peak (eq1) 915 ]. Under ${ }^{\circ}$ ideal ${ }^{\circ}$ conditions $^{\circ}$ such $^{\circ}$ as $\%$ omogenous electric field, homogeneous drift gas, well defined ion gating, and minimal contributions from space charging, the contribution to the measured peak width are ion gate pulse width and diffusion. This relationship can be expressed ${ }^{\circ} \mathrm{s}^{\circ}[31]$ :

$$
t_{1 / 2}^{2}=t_{g}^{2}+\frac{16 \ln 2 k_{b}}{q} \cdot \frac{T t_{D}^{2}}{V}
$$

where $t_{1 / 2}$ is the width of the peak at half-height, $t_{g}$ is the ion gate pulse width, $k_{b}$ is Boltzmann's constant, $q$ is the charge of the ion, $T$ is temperature, $t_{D}$ is the drift time and $V$ is the voltage drop across the drift cell. The resolving power maximum for a given system is the point at which both contributions to peak width are minimized while still permitting a sufficient level of ion-neutral interactions to occur and facilitating separation. Practically, this is achieved by minimizing gate pulse width and increasing the ${ }^{\circ}$ electric $^{\circ}$ field ${ }^{\circ}$ strength ${ }^{\circ}$ of ${ }^{\circ}$ the $^{\circ}$ system..$^{\circ}$ Figure ${ }^{\circ} 3 a^{\circ}$ illustrates the experimentally determined resolving power curves for (leucine enkephalin) ${ }^{+}$in nitrogen as a function of E/N or Townsend number. These data were acquired using an ion gate pulse width of $100 \mu$ s with pressures of 4,8 , and 12 torr and varying electric field strengths. On average, the maximum resolving power for each pressure was observed at $E / N$ values of $11.4 \mathrm{Td}$ with the highest $R_{p}$ at 4 torr being 51 and 80 at 12 torr. The drift times and $p / V$ 


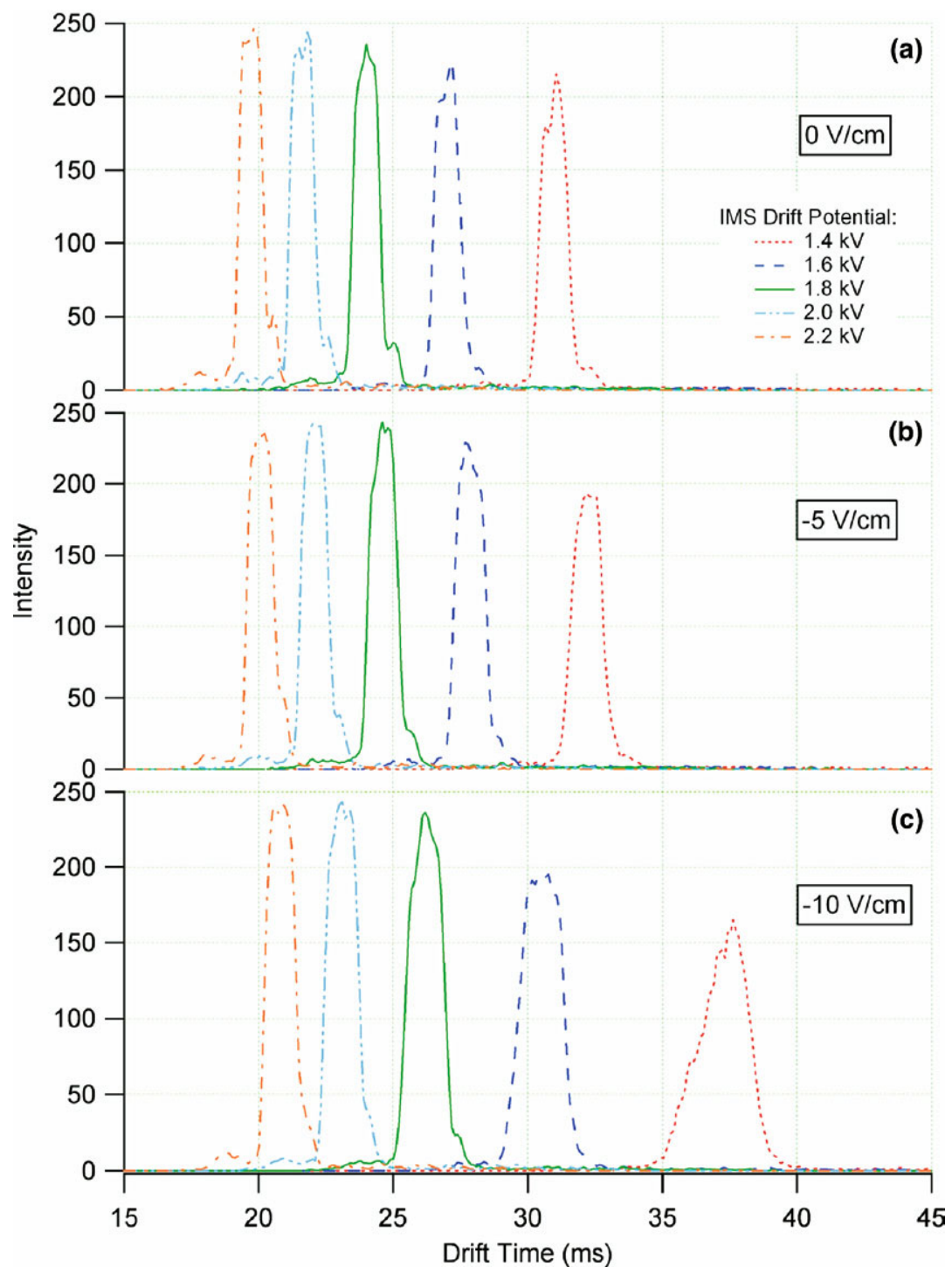

Figure 2. Influence of electric field differential on ion drift time when the drift cell and rear ion funnel are at (a) the same field, (b) the drift cell is $5 \mathrm{~V} / \mathrm{cm}$ higher than the ion funnel, and (c) the drift cell is $10 \mathrm{~V} / \mathrm{cm}$ higher than the ion funnel. The small features in each ATD represent less abundant (bradykinin) ${ }^{2+}$ conformations. Pressure: 4 torr nitrogen.

values of each $\mathrm{E} / \mathrm{N}$ value were plotted to make certain they were in the low field limit and independent of electric field. The high degree of linearity of each plot $\left(R^{2}>\right.$ 0.9999 ) indicated that the data obtained was below the low field limit.

To further demonstrate the $R_{p}$ increase observed at higher drift gas pressures, the ATDs of (leucine enkepha-

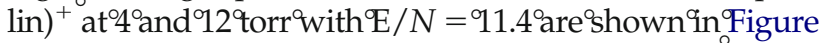
$3 b .{ }^{-}$The ${ }^{\circ}$ single ${ }^{\circ}$ ATD ${ }^{\circ}$ peaks ${ }^{\circ}$ of $^{\circ}$ (leucine enkephalin) ${ }^{+}{ }^{\circ}$ clearly illustrate the decrease in peak width with increasing $R_{p}$. Increased resolving powers at elevated pressures and constant $\mathrm{E} / \mathrm{N}$ ratios are due to the increasing number of ion-neutral interactions that occur at such conditions. Under similar electric field conditions, the ion drift time is a function of drift gas pressure. While higher resolving power at increased pressures has been reported previ-

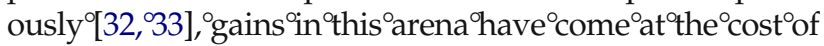

sensitivity (particularly in combination with MS). As outlined above, the addition of the electrodynamic ion funnel has allowed sensitivity (defined by the signal to noise ratio) to be retained while increasing resolving power. Combined with the increases in resolving power at elevated $^{\circ}$ pressures, ${ }^{\circ}$ the ${ }^{\circ}$ intensity ${ }^{\circ}$ levels ${ }^{\circ}$ shown ${ }^{\circ}$ in ${ }^{\circ}$ Figure $^{\circ} 3 \mathrm{~b}$ help further demonstrate the benefits afforded by combining the high-pressure ion funnels with ion mobility spectrometry.

The ability to increase resolving power without greatly compromising sensitivity enhances the utility of IMS as bothoa separation ${ }^{\circ}$ and ${ }^{\circ}$ analysis method. Figure 4 illustrates the nested spectra for a tryptic digest of $0.03 \mathrm{mg} / \mathrm{mL} \mathrm{BSA}$ at 4 and 12 torr. These spectra were both acquired at the $\mathrm{E} / \mathrm{N}$ values determined to produce optimal resolving power $(\sim 11.4 \mathrm{Td})$. For comparison, a $\mathrm{m} / \mathrm{z}$ range from 400 to 800 was chosen for clarity. Similar intensities in the total 

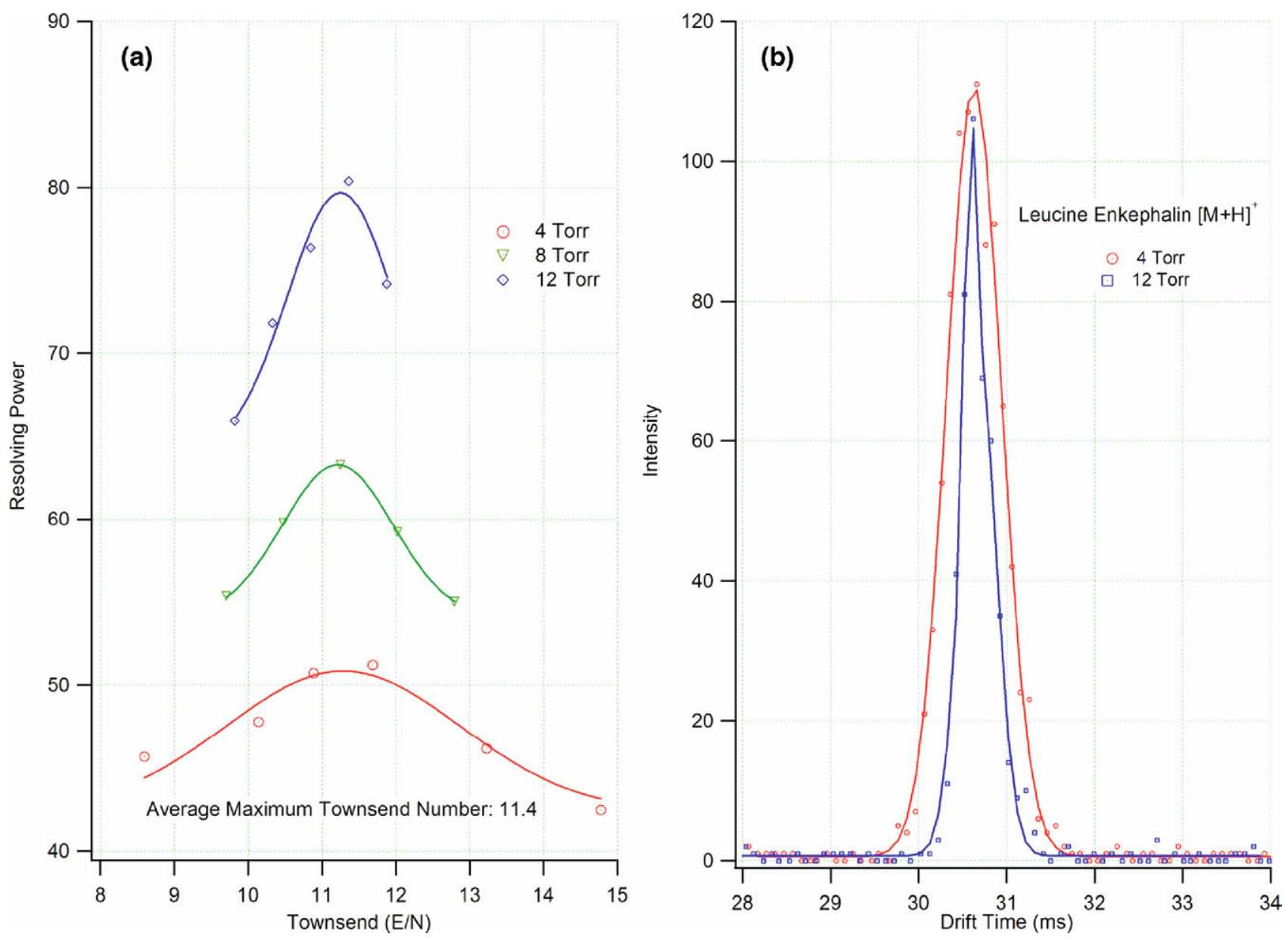

Figure 3. (a) A plot of resolving power versus $\mathrm{E} / \mathrm{N}$ for the +1 charge state of leucine enkephalin at 4,8 , and 12 torr. For all pressures, the maximum resolving power occurred at $\sim 11.4 \mathrm{Td}$. (b) ATDs for the (leucine enkephalin) ${ }^{+}$for $\mathrm{E} / \mathrm{N}=11.4 \mathrm{Td}$ at pressures of 4 and 12 torr.

ion chromatograms (TICs) and mass spectra were observed for each pressure and the higher resolving power at 12 torr nitrogen is highlighted by the increased definition in contoured features. An additional benefit noted for the 12 torr separation of tryptically digested BSA was an increased abundance of larger $\mathrm{m} / \mathrm{z}$ components. This occurrence is believed to arise from the behavior of large ion populations within the ion trap and the consequent reduction of singly charged species that contribute to chemical noise. In the following section, this observation is discussed in greater detail.

\section{Drift Gas Selection: He Versus $\mathrm{N}_{2}$}

Due to the large number of ion-neutral cross section data reported for helium drift gas, similar experiments were conducted for comparison. Experimental collision cross sections were determined for bradykinin, myoglobin, ubiquitin, and cytochrome $c$ using the technique outlined in the Experimental section. Only extended (i.e., higher) charge states of myoglobin, ubiquitin, and cytochrome $c$ were compared with literature values as the degree of unfolding and instrumental resolving power vary between ion mobility systems used to determine the values reported. The experimentally measured cross sections for the peptides and proteins mentioned above using the ESI-IMS-TOF MS instrument and the associated difference compared with the literature values $^{\circ}$ are $^{\circ}$ shown $^{\circ}$ in $^{\circ}$ Table $^{\circ} 1 .^{\circ}$ In $^{\circ}$ all $^{\circ}$ cases $^{,}{ }^{\circ}$ the ${ }^{\circ}$ values obtained with the current ESI-IMS-TOF MS instrument were within $2 \%$ of the reported literature values.

After verifying the accuracy of the measurements using our system compared with the literature values, the TICs and ATDs in helium for the selected proteins were compared with their corresponding TICs and ATDs in nitrogen. Currently, few reports exist that compare the spectra for biomolecules measured in nitrogen to their corresponding ${ }^{\circ}$ spectra ${ }^{\circ}$ in ${ }^{\circ}$ helium $[34,35] .{ }^{\circ}$ Drift $^{\circ}$ gas $^{\circ}$ comparison experiments were performed at 4 torr (due to the $\mathrm{E} / \mathrm{N}$ limits imposed by helium and its associated breakdown potential) using the same sample solutions at $5 \mu \mathrm{M}$ concentrations. A subset of the data obtained from these comparison'studies are shown in Figures $5{ }^{\circ}$ and $\%$. The two plots $^{\circ}$ in ${ }^{\circ}$ Figure $^{\circ} 5^{\circ}$ illustrate ${ }^{\circ}$ the ${ }^{\circ}$ TICs $^{\circ}$ for $^{\circ}$ cytochrome $^{\circ} \mathrm{C}$ in nitrogen and helium, and the ATDs for the +15 and +19 charges states are highlighted. From the TICs, it was 


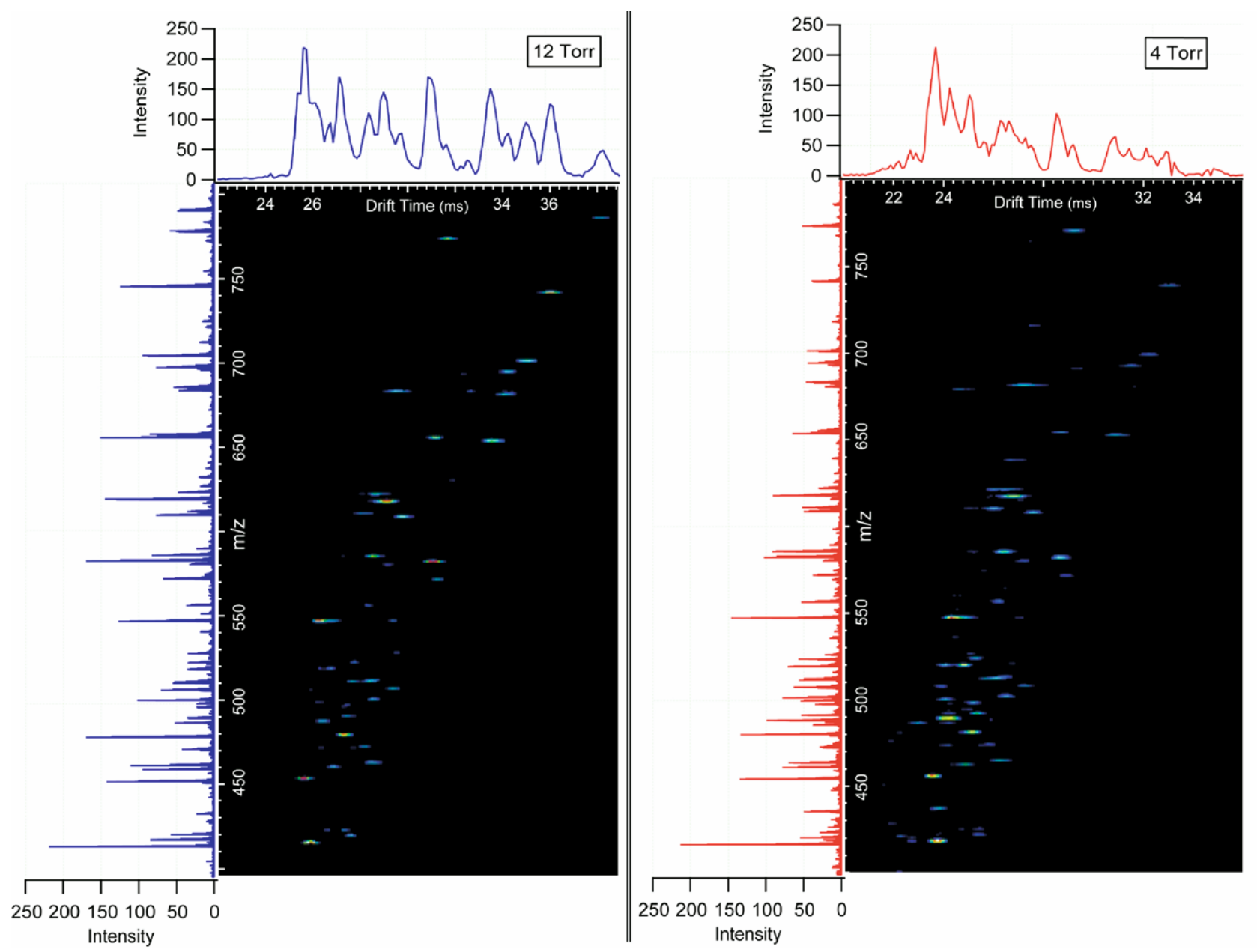

Figure 4. A section of a nested BSA tryptic digest spectrum taken at 12 torr (left) and 4 torr (right) where drift time is displayed on the $\mathrm{x}$-axis and $\mathrm{m} / \mathrm{z}$ on the y-axis. The total ion chromatograms are displayed above the nested spectra and the integrated mass spectrum for each is on the left. The smaller spot sizes of the 12 torr nested spectrum indicate the increase in resolving power from the 4 torr separation.

evident that the relative signal intensities of the different charge states of cytochrome $c$ were approximately 3-fold higher in nitrogen than in helium at ion funnel trapping

Table 1. Experimental and literature values for protein cross sections $\left(\AA^{2}\right)$ in helium

\begin{tabular}{|c|c|c|c|}
\hline & $\Omega_{\text {Expt }}{ }^{a}$ & $\Omega_{\text {Literature }}$ & $\%$ Difference \\
\hline (Bradykinin) $^{2+}$ & 236 & $240^{b}$ & $1.7 \%$ \\
\hline (Myoglobin) $^{18+}$ & 3434 & $3489^{c}$ & $1.6 \%$ \\
\hline (Myoglobin) $^{19+}$ & 3558 & $3570^{c}$ & $0.03 \%$ \\
\hline (Myoglobin) $^{20+}$ & 3632 & $3682^{c}$ & $1.4 \%$ \\
\hline (Myoglobin) $^{21+}$ & 3729 & $3792^{c}$ & $1.7 \%$ \\
\hline (Myoglobin) $^{22+}$ & 3788 & $3815^{c}$ & $0.7 \%$ \\
\hline (Ubiquitin) $^{9+}$ & 1612 & $1649^{d}$ & $2.2 \%$ \\
\hline (Ubiquitin) $^{10+}$ & 1698 & $1732^{d}$ & $2.0 \%$ \\
\hline$(\text { Cytochrome } c)^{12+}$ & 2294 & $2335^{\mathrm{e}}$ & $1.8 \%$ \\
\hline$(\text { Cytochrome } c)^{13+}$ & 2346 & $2391^{\mathrm{e}}$ & $1.9 \%$ \\
\hline$(\text { Cytochrome } c)^{14+}$ & 2435 & $2473^{e}$ & $1.5 \%$ \\
\hline
\end{tabular}

${ }^{\mathrm{a}} 1 \%$ reproducibility error.

${ }^{\mathrm{b}}$ Reference [44].

${ }^{\mathrm{c} R e f e r e n c e ~[38] .}$

${ }^{\mathrm{d}}$ Reference [45].

eReference [46]. times of $60 \mathrm{~ms}$ and that the +19 charge state of the cytochrome $c$ ion was suppressed in He compared to $\mathrm{N}_{2}$. It was also observed that the low charge state solvent ions were much more abundant in helium than in nitrogen.

To identify the source of these apparent discrimination effects for the $\mathrm{He}$ and $\mathrm{N}_{2}$ drift gases, the trapping time of ions before each ion mobility pulse was varied. This experiment served to examine the role of ion population in the ion trap. From these experiments, it was found that for trapping times greater than $2 \mathrm{~ms}$ at 4 torr, ion signals for the cytochrome $c$ ions in $\mathrm{N}_{2}$ were increasingly higher than the cytochrome $c$ ion intensities $^{\circ}$ in $^{\circ} \mathrm{He}^{\circ}$ ( see $^{\circ}$ Figure $^{\circ} 5^{\circ}$ as $^{\circ}$ an $^{\circ}$ example). ${ }^{\circ} \mathrm{To}^{\circ}$ interpret these observations, computer simulations were conducted using an ion funnel trapping model modified to reflect $^{\circ}$ the ${ }^{\circ}$ current $^{\circ}$ experimental ${ }^{\circ}$ configuration $^{\circ}[36]$.

While a detailed description of the behavior of ions with respect to electric fields is beyond the scope of this discussion, a brief exploration of relevant topics is warranted to further elucidate the data obtained from the current ion mobility instrument and interpret the ion funnel model. During the course of an experiment, 


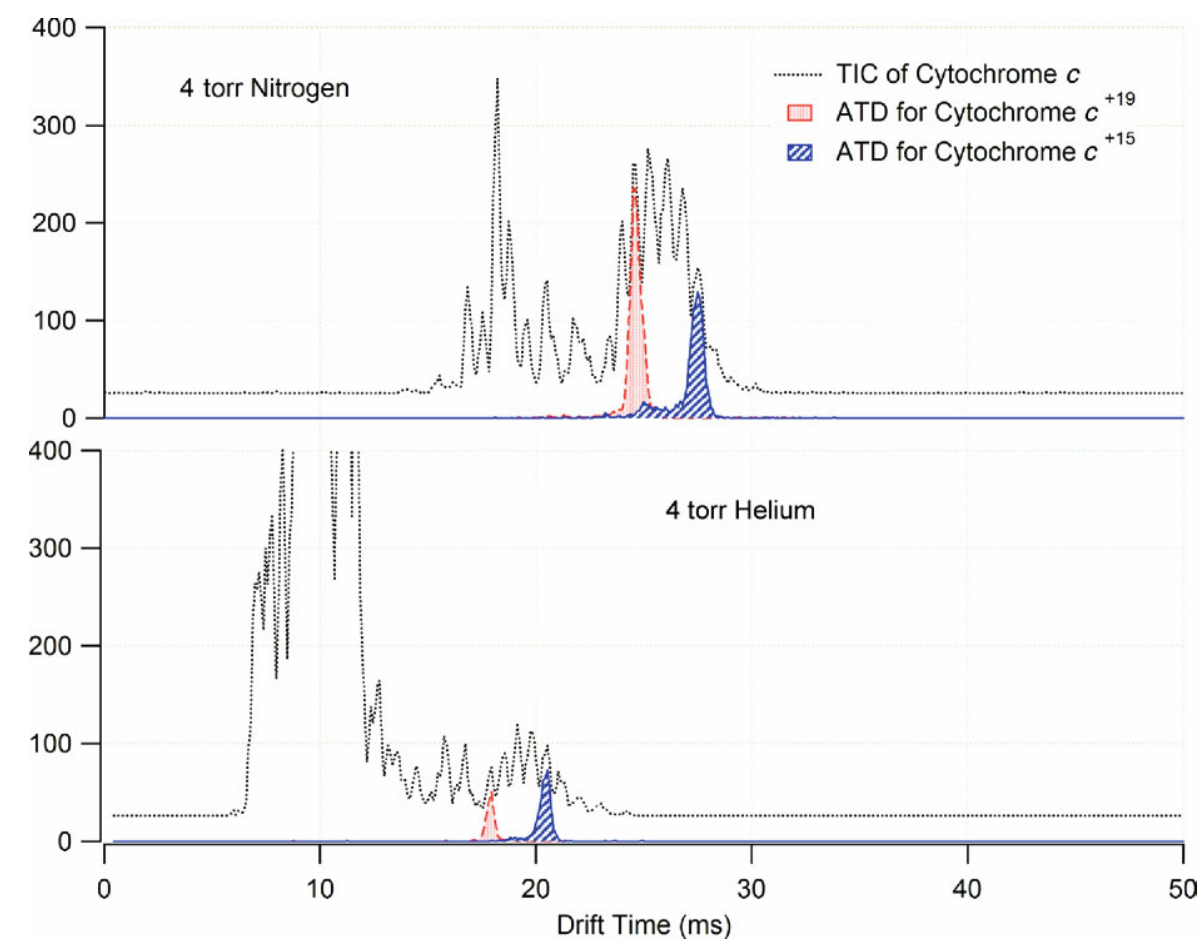

Figure 5. The TICs and ATDs for the +15 and +19 charge states of cytochrome $c$ in $\mathrm{N}_{2}$ (top panel) and $\mathrm{He}$ (bottom panel). The same $5 \mathrm{iM}$ cytochrome $c$ solution was used in both cases. The TICs illustrate that in $\mathrm{N}_{2}$, the high charge state cytochrome $c$ ions have similar intensity to the low charge state solvent ions in the spectra, while in He the low charge state solvent ions are much more abundant than the cytochrome $c$ ions.

the measured ion velocity is proportional to the established electric field through a proportionality constant, $\mathrm{K}$, otherwise know as the ion mobility (see eq 2). This macroscopic velocity arises from a series of micro-scale accelerations and decelerations that occur as ions interact with the ion funnel RF electric field and neutral drift gas. The transition from micro-scale accelerations to the macroscopic or steady-state velocity occurs over a time period, $\tau$, also known as the velocity relaxation time. The parameter, $\tau$ is more formally defined as the characteristic time of the collisional relaxation of the ion's velocity ${ }^{\circ}$ moving ${ }^{\circ}$ through ${ }^{\circ} a^{\circ}$ buffer $^{\circ}$ gas $^{\circ}$ of ${ }^{\circ}$ mass,,$M$ [37]..$^{\circ}$ It should be noted that the variable, $\tau$, used in this discussion differs from the mean time between collisions often referred ${ }^{\circ}$ to $^{\circ}$ in ${ }^{\circ}$ reference $^{\circ}[14]^{\circ}$ using $^{\circ}$ the ${ }^{\circ}$ same $^{\circ}$ variable. ${ }^{\circ}$ From this micro-scale perspective the ion mobility is related to the velocity relaxation time as follows:

$$
K=\frac{\tau \cdot z e}{m}
$$

where, $m$ is the ion mass, $z$ is the number of charges, and e is the elementary charge. Using the relationships previously derived that relate the experimental parameters of pressure, temperature, applied potential (both RF and DC), ion funnel geometry, molecular mass, and molecular cross section, the velocity relaxation time and pressure dependent coefficient of the effective potential, $\gamma$, may be calculated. Using the above experimental parameters and $\mathrm{a}^{\circ}{\text { } \text { cross }^{\circ} \text { section }^{\circ} \text { of }^{\circ} 2679^{\circ} \AA^{\circ}[2]^{\circ} \text { (corresponding }}^{\circ}$ to $^{\circ}$ the $^{\circ}+16$ charge ${ }^{\circ}$ state ${ }^{\circ} f^{9}$ the ${ }^{\circ}$ cytochrome ${ }^{\circ} \mathrm{C}$ [38] $)^{\text {the }}$ thollowing ${ }^{\circ}$ values for $\gamma$ and $\tau$ were found in $\mathrm{He}$ and $\mathrm{N}_{2^{\circ}}$ [37]:

$$
\begin{aligned}
& \gamma(p)=\frac{\omega^{2} \tau^{2}}{1+\omega^{2} \tau^{2}} \\
& 4 \text { Torr He: } \quad \tau \approx 0.54 \times 10^{-6} \mathrm{~s}, \quad \gamma \sim 0.73 \\
& 4 \text { Torr } \mathrm{N}_{2}: \quad \tau \approx 0.2 \times 10^{-6} \mathrm{~s}, \quad \gamma \sim 0.28
\end{aligned}
$$

where $\omega$, is the angular frequency corresponding to the RF frequency $\mathrm{f}$ as $\omega=2 \pi \mathrm{f}$.

Since the pressure dependent coefficient of the effective potential, $\gamma$, is related to the trapping efficiency of an RF ion guide, the model suggests that the ion funnel operating at 4 torr He had a $\sim 2.6$-fold greater ion trapping efficiency compared to 4 torr $\mathrm{N}_{2}$. Since the actual trapping time necessary for an IMS experiment $(\sim 60 \mathrm{~ms})$ is long enough to fill the trap in both $\mathrm{He}$ and $\mathrm{N}_{2}$, more ions will be present in the trap for He due to the higher trapping efficiency. However, the larger ion population in $\mathrm{He}$ causes a stronger space charge effect in the trap at extended ion accumulation times resulting in charge stratification ${ }^{\circ}[39-41]{ }^{\circ}$ which ${ }^{\circ}$ tends ${ }^{\circ}$ to $^{\circ}$ suppress $^{\circ}$ high $^{\circ} \mathrm{m} / \mathrm{z}$ ions . Thus, while the ion trapping efficiency is increased for $\mathrm{He}$ compared to $\mathrm{N}_{2}$, the physical space available for accumulation of higher charge states is reduced by space charge induced discrimination. The charge discrimination effects observed ${ }^{\circ}$ in $^{\circ}$ the ${ }^{\circ}$ experiment ${ }^{\circ}$ as ${ }^{\circ}$ highlighted ${ }^{\circ}{ }^{\circ}{ }^{\circ}$ Figure ${ }^{\circ}{ }^{\circ}$ are 


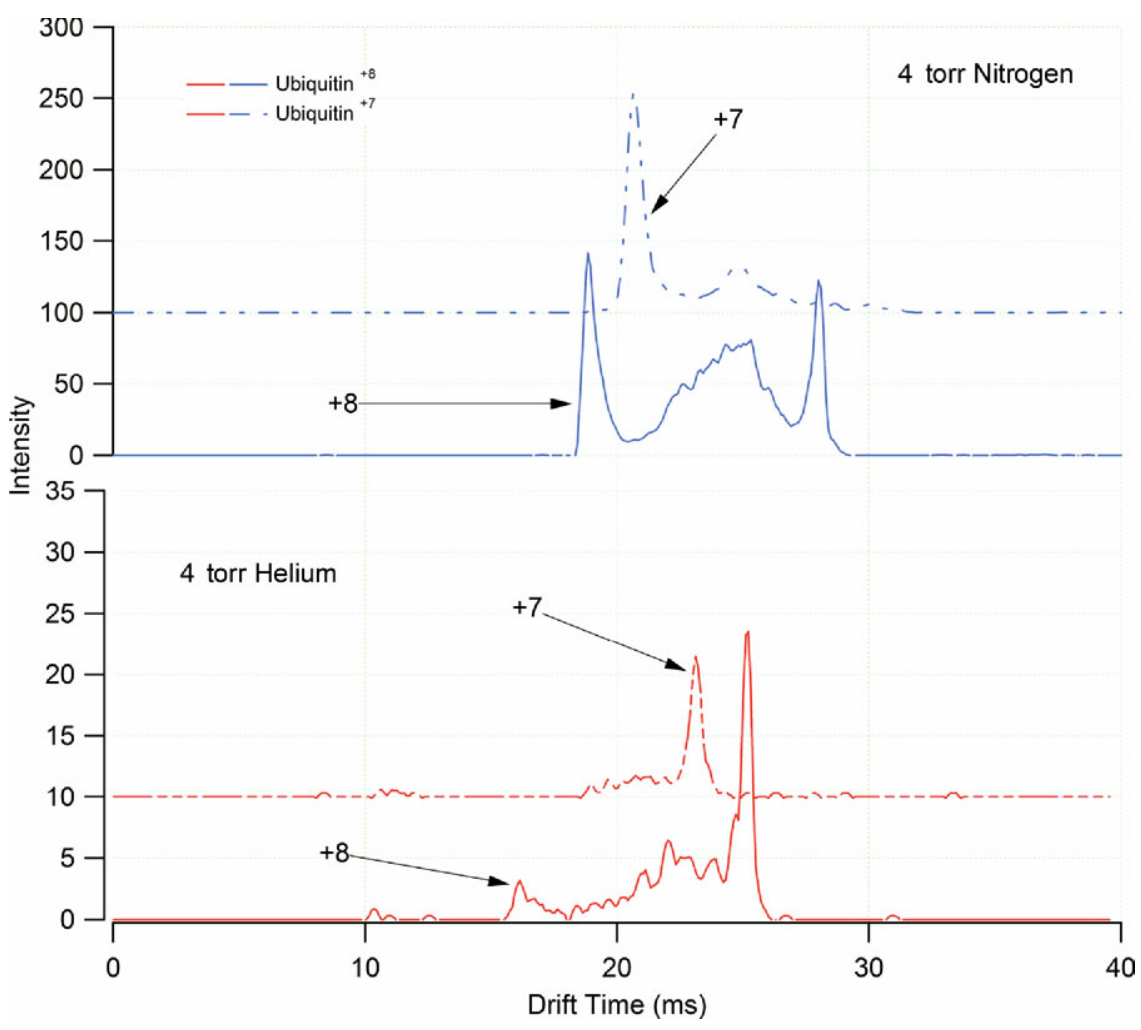

Figure 6. ATDs of the +7 and +8 charge states of ubiquitin in $\mathrm{N}_{2}$ (top panel) and He (bottom panel) buffer gases. The same $5 \mathrm{iM}$ ubiquitin solution was used for both experiments. The more compact conformer of both charge states of ubiquitin appears to be more stable in $\mathrm{N}_{2}$ as the more extended conformer is more prevalent in He.

consistent with the explanation described here and have also been observed in other IMS instruments that utilize ion $^{\circ}$ funnel ${ }^{\circ}$ technolog $y^{\circ}[30]^{\circ} ;$ further ${ }^{\circ}$ optimization $^{\circ}$ of $^{\circ}$ the trap parameters will allow us to suppress the unwanted discrimination effects.

Another interesting observation from the comparison of the helium and nitrogen ATDs was that more compact ion conformations were favored in $\mathrm{N}_{2}$ as illustrated ${ }^{\circ}$ in ${ }^{\circ}$ Figures ${ }^{\circ} 5^{\circ}$ and $^{\circ} 6$. In ${ }^{\circ}$ Figure ${ }^{\circ} 6$, the ${ }^{\circ}$ ATDs ${ }^{\circ}$ for the +7 and +8 charge states of ubiquitin in both drift gases are shown. Because drift time is directly proportional to collision cross section, more compact ion conformations (e.g., shorter drift time) were observed for the two charge states of ubiquitin in $\mathrm{N}_{2}$, while the ATDs in He suggest more extended conformations. In a fashion similar to the behavior outlined ${ }^{\circ}$ for ${ }^{\circ}$ Figure 5 , the increased space charge effect in the RF ion trap also leads to an increased collisional activation of ions, indicating that a higher degree of collisional ion heating may occur in 4 torr He because of the larger ion population $\left[42,{ }^{\circ} 43\right] .^{\circ}{ }^{\circ}$ This ${ }^{\circ}$ expectation ${ }^{\circ}$ was $^{\circ}$ confirmed $^{\circ}$ by a larger signal for the more extended conformation of the ${ }^{\circ}$ ubiquitin ${ }^{\circ}+7^{\circ}$ and $^{\circ}+8^{\circ}$ ions $^{\circ}$ (Figure ${ }^{\circ} 6$ ) .

In addition to the ion collisional heating induced by the space charge effects, a concurrent phenomenon related to ion funnel RF heating may also contribute to the unfolding of compact conformers. The relationships that govern steady-state drift motion become applicable for experimental times that exceed the velocity relaxation ${ }^{\circ}$ time, ${ }^{\circ} \tau^{\circ}[14] . .^{\circ}$ Using $^{\circ}$ the $^{\circ}$ Classical $^{\circ}$ definition ${ }^{\circ}$ of ${ }^{\circ}$ ion mobility (eq 5), $T_{\text {eff }}$ as the effective temperature, and $M$ for the mass of the drift gas, the following relationship expresses the degree of ion heating expected:

$$
T_{e f f}-T=\frac{M v_{d}}{3 k_{b}}=\frac{M K^{2} E^{2}}{3 k_{b}} \approx \frac{E^{2}}{\Omega^{2}}
$$

During the course of an ion mobility experiment operating within the low field limit, the overall effective temperature experienced by the ion is often less than a few degrees K. However, conformer unfolding, similar to ${ }^{\circ}$ the ${ }^{\circ}$ data $^{\circ}$ shown $^{\circ}$ in ${ }^{\circ}$ Figure $^{\circ}{ }^{\circ},{ }^{\circ}$ is ${ }^{\circ}$ often ${ }^{\circ}$ observed $^{\circ}$ for protein measurements using ion mobility, indicating that a few degrees of heating during an experiment may be sufficient to induce conformational shifts. This effect may be intensified when ions are trapped for extended times within the ion funnel, which not only has a DC field but also an effective RF potential. The degree of ion heating associated with the ion funnel DC field is not expected to exceed that of subsequent ion mobility experiments, however, the RF heating can be significant depending on the RF amplitude and ion trapping time. Because the effective potential within a stacked ring RF device decreases with the exponential distance squared from the electrode, ions close to the funnel electrode will experience more RF heating than the ions in the middle of 
the ion funnel. Therefore, experimental conditions that promote an increased level of space charge induced radial expansion will also raise the effective temperature of the ion populations trapped in the ion funnel. The virtual absence of the compact form of the +8 charge state of ubiquitin in 4 torr $\mathrm{He}$ is a primary example of such behavior. From the generalization in eq 10, the degree of ion heating for ions of the same $\mathrm{m} / \mathrm{z}$ will be also increased for ion populations possessing a more compact gas-phase conformation. It should be noted that the magnitude of ion heating described is sufficient to induce conformational changes but below the level necessary for ion dissociation as this event is not seen experimentally.

To address the issues contributing to excessive space charge in the ion funnel, future developments will include more exclusive control of the time ions are accumulated within the trap and further optimization of trap geometry to maximize charge capacity. Additionally, the implementation of an adjustable low $\mathrm{m} / \mathrm{z}$ filter to reduce overall ion population should also minimize mass discrimination effects associated with space charge.

\section{Summary}

We have introduced a new ESI-IMS-TOF MS design that utilizes high-pressure electrodynamic ion funnels on either side of the drift cell. These ion funnels allow the ion mobility drift cell pressure to be increased, effectively increasing IMS resolution without sacrificing sensitivity. Further characterization of the ESI-IMS-TOF instrument illustrated that:

1. The rear ion funnel operates as part of the drift cell so the field must be matched in the IMS and ion funnel regions to ensure accuracy for experimentally determined collision cross section.

2. Modifications of previous ion funnel configurations allowed the ESI-IMS-TOF drift cell pressure to be increased from 4 to 12 torr without substantial loss of sensitivity. An additional benefit of increasing drift gas pressure was the increase of resolving power from 50 at 4 torr to 80 at 12 torr.

3. Measurements of collision cross sections in both helium and nitrogen agree with those reported previously (within $2 \%$ ) using other hybrid ion mobility instruments.

4. Different levels of protein charge states and conformations were observed using N2 and $\mathrm{He}$ as drift gases. Modeling of the experimental system suggests space charge induced mass discrimination effects contribute not only to relative ratios of the observed ions but also to their conformations. From this model and experimental evidence, further ion funnel developments are necessary to avoid overfilling the trap, as mass discrimination and ion heating appear to be a consequence of this event.

\section{Acknowledgments}

The authors thank M. Buschbach (PNNL) for his critical help with instrument and software development and Dr. Alexandre Shvartsburg for insightful discussions about ion funnels. Portions of this work were supported by PNNL Laboratory Directed Research and Development Program, the NIH National Center for Research Resources (RR018522), and the NCI (R21 CA12619-01). Pacific Northwest National Laboratory is operated by the Battelle Memorial Institute for the U.S. Department of Energy through contract DE-AC05-76RLO1830.

\section{References}

1. Fenn, J. B.; Mann, M.; Meng, C. K.; Wong, S. F.; Whitehouse, C. M. Electrospray Ionization-Principles and Practice. Mass Spectrom. Rev. 1990, 9, 37-70.

2. Wolters, D. A.; Washburn, M. P.; Yates, J. R. An Automated Multidimensional Protein Identification Technology for Shotgun Proteomics. Anal Chem. 2001, 73, 5683-5690.

3. Peng, J.; Elias, J. E.; Thoreen, C. C.; Licklider, L. J.; Gygi, S. P. Evaluation of Multidimensional Chromatography Coupled with Tandem Mass Spectrometry (LC/LC-MS/MS) for Large-Scale Protein Analysis: The Yeast Proteome. J. Proteome Res. 2003, 2, 43-50.

4. Shen, Y.; Zhao, R.; Berger, S. J.; Anderson, G. A.; Rodriguez, N.; Smith, R. D. High-Efficiency Nanoscale Liquid Chromatography Coupled On-Line with Mass Spectrometry Using Nanoelectrospray Ionization for Proteomics. Anal. Chem. 2002, 74, 4235-4249.

5. Bowers, M. T.; Kemper, P. R.; von Helden, G.; van Koppen, P. A. M. Gas-Phase Ion Chromatography: Transition Metal State Selection and Carbon Cluster Formation. Science 1993, 260, 1446-1451.

6. Clemmer, D. E.; Jarrold, M. F. Ion Mobility Measurements and Their Applications to Clusters and Biomolecules. J. Mass Spectrom. 1997, 32, 577-592.

7. Wyttenbach, T.; Bowers, M. T. Gas-Phase Conformations: The Ion Mobility/Ion Chromatography Method. Top. Curr. Chem. 2003, 225, 207-232.

8. Valentine, S. J.; Counterman, A. E.; Hoaglund, C. S.; Reilly, J. P.; Clemmer, D. E. Gas-Phase Separations of Protease Digests. J. Am. Soc. Mass Spectrom. 1998, 9, 1213-1216.

9. Henderson, S. C.; Valentine, S. J.; Counterman, A. E.; Clemmer, D. E. ESI/Ion Trap/Ion Mobility/Time-of-Flight Mass Spectrometry for Rapid and Sensitive Analysis of Biomolecular Mixtures. Anal. Chem. 1999, 71, 291-301.

10. Valentine, S. J.; Kulchania, M.; Srebalus Barnes, C. A.; Clemmer, D. E. Multidimensional separations of complex peptide mixtures: A combined high-performance liquid chromatography/ion mobility/time-offlight mass spectrometry approach. Int. J. Mass Spectrom. 2001, 212, 97-109.

11. Lee, Y. J.; Hoaglund-Hyzer, C. S.; Srebalus Barnes, C. A.; Hilderbrand, A. E.; Valentine, S. J.; Clemmer, D. E. Development of High-Throughput Liquid Chromatography Injected Ion Mobility Quadrupole Time-of-Flight Techniques for Analysis of Complex Peptide Mixtures. J. Chromatog. B. 2002, 782, 343-351.

12. Adkins, J. N.; Varnum, S. M.; Auberry, K.J.; Moore, R. J.; Angell, N. H. Smith, R. D.; Springer, D. L.; Pounds, J. G. Toward a Human Blood Serum Proteome: Analysis by Multidimensional Separation Coupled with Mass Spectrometry. Mol. Cell. Proteomics 2002, 1, 947-955.

13. Tirumalai, R. S.; Chan, K. C.; Prieto, D. A.; Issaq, H. J.; Conrads, T. P.; Veenstra, T. D. Characterization of the Low Molecular Weight Human Serum Proteome. Mol. Cell. Proteomics 2003, 2, 1096-1103.

14. Mason, E. A.; McDaniel, E. W. Transport Properties of Ions in Gases; Wiley: New York, 1988.

15. Rivercomb, H. E.; Mason, E. A. Theory of Plasma Chromatography/ Gaseous Electrophoresis. Anal. Chem. 1975, 47, 970-983.

16. Strittmatter, E. F.; Kangas, L. J.; Petritis, K.; Mottaz, H. M.; Anderson, G. A.; Shen, Y.; Jacobs, J. M.; Camp, D. G.; Smith, R. D. Application of Peptide LC Retention Time Information in a Discriminant Function for Peptide Identification by Tandem Mass Spectrometry. J. Proteome Res. 2004, 3, 760-769.

17. Tang, K.; Shvartsburg, A. A.; Lee, H. N.; Prior, D. C.; Buschbach, M. A.; Li, F. M.; Tolmachev, A. V.; Anderson, G. A.; Smith, R. D. HighSensitivity Ion Mobility Spectrometry/Mass Spectrometry Using Electrodynamic Ion Funnel Interfaces. Anal. Chem. 2005, 77, 3330-3339.

18. Ibrahim, Y.; Tang, K. Q.; Tolmachev, A. V.; Shvartsburg, A. A.; Smith R. D. Improving Mass Spectrometer Sensitivity Using a High-Pressure Electrodynamic Ion Funnel Interface. J. Am. Soc. Mass Spectrom. 2006, 17 1299-1305.

19. Kelly, R. T. Page, J. S.; Luo, Q ; Moore, R. J ; Orton, D. J.; Tang, K.; Smith, R. D. Chemically Etched Open Tubular and Monolithic Emitters for Nanoelectrospray Ionization Mass Spectrometry. Anal. Chem. 2006, 78, 7796-7801.

20. Kim, T.; Tolmachev, A. V.; Harkewicz, R.; Prior, D. C.; Anderson, G. A. Udseth, H. R.; Smith, R. D.; Bailey, T. H.; Rakov, S.; Futrell, J. H. Design 
and Implementation of a New Electrodynamic Ion Funnel. Anal. Chem. 2000, 72, 2247-2255.

21. Kim, T.; Tang, K. Q.; Udseth, H. R.; Smith, R. D. A Multicapillary Inlet Jet Disruption Electrodynamic Ion Funnel Interface for Improved Sensitivity Using Atmospheric Pressure Ion Sources. Anal. Chem. 2001, 73, 4162-4170.

22. Smith, R. D.; Kim, T.; Tang, K. Q.; Udseth, H. R. U.S. Patent 6,583,408, 2003.

23. Kemper, P. R.; Bowers, M. T. A Hybrid Double-Focusing Mass Spectrometer-High-Pressure Drift Reaction Cell to Study Thermal Energy Reactions of Mass-Selected Ions. J. Am. Soc. Mass Spectrom. 1990, 1, 197-207.

24. von Helden, G.; Gotts, N.; Bowers, M. T. Annealing of Carbon Cluster Cations: Rings to Rings and Rings to Fullerenes. J. Am. Chem. Soc. 1993, 115, 4363-4364.

25. Gidden, J.; Kemper, P. R.; Shammel, E.; Fee, D. P.; Anderson, S. E.; Bowers, M. T. Application of Ion Mobility to the Gas-Phase Conformational Analysis of Polyhedral Oligomeric Silsesquioxanes. Int. J. Mass Spectrom. 2003, 222, 63-73.

26. von Helden, G.; Hsu, M.-T.; Kemper, P. R.; Bowers, M. T. Structures of carbon cluster ions from 3 to 60 atoms: Linears to rings to fullerenes. J. Chem. Phys. 1991, 95, 3835-3837.

27. Page, J. S.; Tolmachev, A. V.; Tang, K.; Smith, R. D. Variable low-mass filtering using an electrodynamic ion funnel. J. Mass Spectrom. 2005, 40, 1215-1222.

28. Wyttenbach, T.; Kemper, P. R.; Bowers, M. T. Design of a New Electrospray Ion Mobility Mass Spectrometer. Int. J. Mass Spectrom. 2001, 212, 13-23.

29. Merenbloom, S. I.; Koeniger, S. L.; Valentine, S. J.; Plasencia, M. D.; Clemmer, D. E. IMS-IMS and IMS-IMS-IMS/MS for Separating Peptide and Protein Fragment Ions. Anal. Chem. 2006, 78, 2802-2809.

30. Koeniger, S. L.; Merenbloom, S. I.; Valentine, S. J.; Jarrold, M. F.; Udseth, H. R.; Smith, R. D.; Clemmer, D. E. An IMS-IMS Analogue of MS-MS. Anal. Chem. 2006, 78, 4161-4174.

31. Siems, W. F.; Wu, C.; Tarver, E. E.; Hill, H. H.; Larsen, P. R.; McMinn, D. G. Measuring the Resolving Power of Ion Mobility Spectrometers. Anal. Chem. 1999, 66, 4195-4201.

32. Wu, C.; Siems, W. F.; Klasmeier, J.; Hill, H. H. Separation of Isomeric Peptides Using Electrospray Ionization/High-Resolution Ion Mobility Spectrometry. Anal. Chem. 2000, 72, 391-395.

33. Dugourd, P.; Hudgins, R. R.; Clemmer, D. E.; Jarrold, M. F. HighResolution Ion Mobility Measurements. Rev. Sci. Instrum. 1997, 68, 1122-1129.
34. Hill, H. H.; Hill, C. H.; Asbury, G. R.; Wu C.; Matz, L. M.; Ichiye, T. Charge Location on Gas Phase Peptides. Int. J. Mass Spectrom. 2002, 219, 23-27.

35. Beegle, L. W.; Kanik, I.; Matz, L.; Hill, H. H. Effects of Drift-Gas Polarizability on Glycine Peptides in Ion Mobility Spectrometry. Int. I. Mass Spectrom. 2002, 216, 257-268.

36. Tolmachev, A. V.; Kim, T. Udseth, H. R.; Smith, R. D.; Bailey, T. H. Futrell, J. H. Simulation-Based Optimization of the Electrodynamic Ion Funnel for High Sensitivity Electrospray Ionization Mass Spectrometry. Int. J. Mass Spectrom. Ion Processes 2000, 203, 31-47.

37. Tolmachev, A. V.; Chernushevich, I. V.; Dodonov, A. F.; Standing, K. G. A Collisional Focusing Ion Guide for Coupling an Atmospheric Pressure Ion Source to a Mass Spectrometer. Nucl. Instrum. Methods Phys. Res. B. 1997, 124, 112-119.

38. Liu, Y.; Valentine, S. J.; Clemmer, D. E. (unpublished results). http:// www.indiana.edu/ clemmer.

39. Tolmachev, A. V. Udseth, H. R.; Smith, R. D. Radial Stratification of Ions as a Function of Mass to Charge Ratio in Collisional Cooling Radio Frequency Multipoles Used as Ion Guides or Ion Traps. Rapid Commun Mass Spectrom. 2000, 14, 1907-1913.

40. Belov, M. E.; Nikolaev, E. N.; Harkewicz, R.; Masselon, C. D.; Alving, K. Smith, R. D. Ion Discrimination During Ion Accumulation in a Quadrupole Interface External to a Fourier Transform Ion Cyclotron Resonance Mass Spectrometer. Int. J. Mass Spectrom. 2001, 208, 205-225.

41. Tolmachev, A. V.; Udseth, H. R.; Smith, R. D. Modeling the Ion Density Distribution in Collisional Cooling RF Multipole Ion Guides. Int. J. Mass Spectrom. 2003, 222, 155-174

42. Tolmachev, A. V.; Udseth, H. R.; Smith, R. D. Charge Capacity Limitations of Radio Frequency Ion Guides in Their Use for Improved Ion Accumulation and Trapping in Mass Spectrometry. Anal. Chem. 2000, $72,970-978$.

43. Tolmachev, A. V.; Vilkov, A. N.; Bogdanov, B.; Pasa-Tolic, L.; Masselon, C. D.; Smith, R. D. Collisional Activation of Ions in RF Ion Traps and Ion Guides: The effective ion temperature treatment. J. Am. Soc. Mass Spectrom. 2004, 15, 1616-1628.

44. Counterman, A. E.; Valentine, S. J.; Srebalus, C. A.; Henderson, S. C. Hoaglund, C. S.; Clemmer, D. E. High-Order Structure and Dissociation of Gaseous Peptide Aggregates that are Hidden in Mass Spectra. J. Am. Soc. Mass Spectrom. 1998, 9, 743-759.

45. Valentine, S. J.; Counterman, A. E.; Clemmer, D. E. Conformer-Dependent Proton-Transfer Reactions of Ubiquitin Ions. J. Am. Soc. Mass Spectrom. 1997, 8, 954-961.

46. Shelimov, K. B.; Clemmer, D. E.; Hudgins, R. R.; Jarrold, M. F. Protein Structure in Vacuo: Gas-Phase Conformations of BPTI and Cytochrome. c. J. Am. Chem. Soc. 1997, 119, 2240-2248. 